\title{
Semeadura direta de genótipos de arroz irrigado em sucessão a espécies de cobertura de inverno(1)
}

\author{
Valmir Gaedke Menezes ${ }^{(2)}$, Carlos Henrique Paim Mariot(2), Mara Cristina Barbosa Lopes ${ }^{(2)}$, \\ Paulo Regis Ferreira da Silva( ${ }^{(3)}$ e Leandro Leonardo Teichmann ${ }^{(4)}$
}

\begin{abstract}
Resumo - A adoção do sistema de semeadura direta de arroz em sucessão a espécies de cobertura de solo no inverno é uma importante alternativa para possibilitar o cultivo em uma mesma área todos os anos. Com o objetivo de avaliar espécies de cobertura do solo no inverno mais apropriadas para participarem de um sistema de sucessão de culturas com semeadura direta de genótipos de arroz irrigado, conduziu-se um experimento na Estação Experimental do Arroz do Instituto Rio Grandense do Arroz, em Cachoeirinha, RS, nas estações de crescimento de 1996/97, 1997/98 e 1998/99. Os tratamentos constaram de quatro genótipos de arroz irrigado (BRS6, BR-IRGA 409, IRGA 416 e IRGA 417) instalados em semeadura direta, sobre parcelas com as coberturas de aveia-preta (Avena strigosa Scheib), aveia-branca (Avena sativa L.), azevém (Lolium multiflorum Lam.), serradela nativa [Ornithopus micranthus (Benth.) Arechavaleta] e de vegetação espontânea e com solo desnudo (testemunha). Quanto ao rendimento de grãos, houve interação entre sistemas de cobertura de solo e estações de crescimento. Nas três estações de crescimento, somente o arroz cultivado em sucessão à leguminosa serradela nativa apresentou rendimento de grãos similar ao obtido no sistema de cultivo convencional. Por outro lado, o arroz cultivado em sucessão ao azevém foi o único a apresentar rendimento de grãos inferior em relação ao sistema de cultivo convencional nas três estações de crescimento.
\end{abstract}

Termos para indexação: plantas de cobertura, cultivo seqüencial, rendimento de culturas, características agronômicas.

\section{No-tillage system of flooded rice genotypes in succession to winter cover crops}

\begin{abstract}
The intensive use of the paddy soils in the production of flooded rice becomes more and more necessary. In this sense, the adoption of the no-till system of rice in succession to winter cover crops is an important alternative to facilitate the cultivation in the same area every year. A trial was conducted with the purpose to identify more appropriate cover crops for cold season to participate of a succession system with no-till system of flooded rice genotypes at the Estação Experimental do Arroz of Instituto Rio Grandense do Arroz, in Cachoeirinha, RS, Brazil, in the 1996/97, 1997/98 and 1998/99 growing seasons. The treatments consisted of four flooded rice genotypes (BRS6, BR-IRGA 409, IRGA 416 and IRGA 417) installed in no-till system on plots with the grasses black oat (Avena strigosa Scheib), white oat (Avena sativa L.) and rye grass (Lolium multiflorum Lam.); with the legumen "serradela nativa" [Ornithopus micranthus (Benth.) Arechavaleta]; with spontaneous vegetation and with nude soil (check). For grain yield there was interaction between cover crops and growing seasons. In the three growing seasons, only the rice cultivated in succession to the legumen "serradela nativa" presented similar grain yield to that one obtained in the control. On the other hand, the rice cultivated in succession to the rye grass was the only one presenting inferior grain yield in relation to the check in the three growing seasons.
\end{abstract}

Index terms: cover plants, sequential cropping, crop yield, agronomic characters.

\footnotetext{
(1) Aceito para publicação em 27 de outubro de 2000. Trabalho financiado pela Fapergs.

${ }^{(2)}$ Instituto Rio Grandense do Arroz, Estação Experimental do Arroz, Caixa Postal 29, CEP 94930-030 Cachoeirinha, RS E-mail: irgafito@via-rs.net
}

\footnotetext{
(3) Universidade Federal do Rio Grande do Sul (UFRGS), Dep. de Plantas de Lavoura, Caixa Postal 776 CEP 91501-970 Porto Alegre, RS. Bolsista do CNPq. E-mail: plantas@vortex.ufrgs.br

(4)UFRGS. Bolsista da Fapergs. E-mail: saoborjars@uol.com.br
} 


\section{Introdução}

O uso intensivo dos solos de várzea no Rio Grande do Sul torna-se cada vez mais importante, visando ao melhor aproveitamento da infra-estrutura existente, dos insumos utilizados, e da preservação do ambiente, em especial a conservação do solo. O solo, quando bem manejado, tem condições de produzir ano após ano sem reduzir a produtividade, e para isto, é necessário que sejam tomadas algumas providências, tais como: manutenção da fertilidade, manejo de invasoras, uso de sistemas de rotação e sucessão de culturas que visem a sua conservação. Mesmo em cultivos sucessivos de arroz irrigado na mesma área pode-se alcançar altos rendimentos de grãos, desde que ela seja isenta de arroz-vermelho (Oryza sativa L.), haja eficiente controle de plantas daninhas e bom manejo de água, e sejam mantidos níveis adequados de fertilidade (Pauletto et al., 1999).

Silveira et al. (1998) verificaram diminuição do rendimento de grãos de arroz de sequeiro em cultivos consecutivos na mesma área, e que o maior rendimento de grãos é obtido no sistema de semeadura direta. A diminuição da produtividade em cultivo contínuo de arroz de sequeiro em uma mesma área, segundo Ventura et al. (1984), citado por Silveira et al. (1998), deve-se, entre outros fatores, à ocorrência de patógenos do solo (fungos, bactérias e nematóides). Os diferentes sistemas de manejo do solo, incluindo tipos de preparo e rotação de culturas, podem determinar alterações no solo, e, conseqüentemente, proporcionar mudanças qualitativas e quantitativas nos microorganismos e na sua atividade (Balota et al., 1996).

No Estado do Rio Grande do Sul, os solos de várzea são explorados, basicamente, com a cultura do arroz irrigado e pecuária de corte extensiva, aproveitando-se a resteva e a pastagem nativa em intervalos de pousio de dois, três ou mais anos. Esta situação poderia ser modificada por meio da adoção do sistema de semeadura direta, aliado à implantação de espécies de cobertura no inverno, possibilitando o uso mais intensivo dos solos de várzea, mediante o cultivo de arroz nas mesmas áreas todos os anos. No entanto, existem dificuldades de adaptação de muitas espécies aos solos de várzea no inverno, em face da sua topografia plana e das suas propriedades físicas, que, associadas ao clima úmido e à ocorrência de precipitações pluviais elevadas e irregulares nesta estação do ano, lhes conferem baixa permeabilidade, podendo causar estresse hídrico por excesso em espécies não-adaptadas (Menezes et al., 1994).

A interferência da cobertura vegetal é um fator importante quando se trata de sistema de semeadura direta. Esta ocorre pela presença física da palha e da alelopatia, causada pela liberação de substâncias aleloquímicas ao meio, a partir da decomposição de resíduos vegetais no solo (Almeida, 1988), os quais podem causar inibição no crescimento da cultura em sucessão. Em exsudatos de raízes de aveia, foram identificadas substâncias como a escopoletina com ação alelopática, as quais foram capazes de inibir o desenvolvimento de plantas como azevém e trigo (Fay \& Duke, 1977). A eliminação mecânica ou química das culturas de inverno, especificamente para aveia-preta e azevém, deve ser efetuada com pelo menos 20 dias antes da semeadura do milho (Ruedell, 1995), evitando, assim, possíveis efeitos alelopáticos, competição por nitrogênio $(\mathrm{N})$ ou mesmo efeito de resíduos de herbicidas utilizados na dessecação. Entretanto, Neves et al. (1999) concluíram que intervalos de tempo de um a 13 dias entre dessecação da aveia-preta e a semeadura do milho não afetam o desenvolvimento da planta e o rendimento de grãos desta cultura.

$\mathrm{Na}$ escolha de espécies de cobertura de solo no inverno, a relação $\mathrm{C} / \mathrm{N}$ de seus resíduos no solo é um fator importante no controle da quantidade de $\mathrm{N} \mathrm{mi-}$ neral disponível para as plantas (Victoria et al., 1992), principalmente sobre o crescimento inicial da cultura subseqüente de verão. Estudos realizados com a cultura do milho revelaram que materiais com alta relação $\mathrm{C} / \mathrm{N}$, como palha de gramíneas, apresentam menores taxas de decomposição, resultando em menor disponibilidade de $\mathrm{N}$ para a planta no início do desenvolvimento, e, geralmente, em menor rendimento de grãos, em comparação ao milho semeado em sucessão às leguminosas (Pavinato et al., 1994; Da Ros \& Aita, 1996). Isto se deve ao fato de que a adição de resíduos culturais com alta relação $\mathrm{C} / \mathrm{N}$ em quantidades elevadas induz os microrganismos do solo a imobilizar o $\mathrm{N}$ da palha, e, inclusive, parte do $\mathrm{N}$ mineral do solo, para utilizarem o $\mathrm{C}$ na biossíntese 
e também como fonte de energia, reduzindo a disponibilidade de N para a cultura em sucessão (Da Ros $\&$ Aita, 1996). No entanto, a continuidade do processo de decomposição de resíduos reduz a relação $\mathrm{C} / \mathrm{N}$ do solo, uma vez que o $\mathrm{C}$ é perdido na forma de $\mathrm{CO}_{2}$, e o $\mathrm{N}$ é conservado pela formação de massa celular microbiana (Victoria et al., 1992).

Atualmente, no Rio Grande do Sul, o azevém é a principal espécie que vem sendo utilizada para formação de cobertura morta para semeadura direta do arroz. Embora ela venha apresentando desempenho razoável para pastejo e formação de cobertura, os orizicultores buscam alternativas mais favoráveis que proporcionem melhor desempenho da pecuária de corte e efeitos mais significativos sobre o controle de plantas daninhas em arroz irrigado (Dias et al., 1995). Menezes et al. (1994) consideram promissora a possibilidade de consorciação de azevém com serradela nativa, a qual foi identificada em algumas propriedades do Rio Grande do Sul. Trata-se de uma espécie de leguminosa [Ornithopus micranthus (Benth.) Arechavaleta] que apresenta boa adaptação aos solos de várzea e tolera teores de umidade elevados no solo, bom sistema radicular e excelente nodulação. Além de incrementar a cobertura vegetal das várzeas no inverno, pode servir como fonte protéica para animais e beneficiar o solo pela fixação do nitrogênio. Portanto, torna-se uma opção tanto como cobertura na implantação do sistema de semeadura direta, como resíduo cultural a ser incorporado ao solo quando da escolha pelo sistema convencional.

Portanto, é importante o conhecimento de espécies de plantas que se adaptem às condições de solo de várzeas no inverno, que sejam boas formadoras de cobertura, e que não provoquem redução significativa no rendimento do arroz em sucessão, em relação ao sistema convencional de semeadura.

Este trabalho teve por objetivo avaliar espécies de cobertura do solo no inverno mais apropriadas para participarem de um sistema de sucessão de culturas com semeadura direta de genótipos de arroz irrigado.

\section{Material e Métodos}

O experimento foi conduzido durante três estações de crescimento (1996/97, 1997/98 e 1998/99) na Estação
Experimental do Arroz do Instituto Rio Grandense do Arroz, localizada no Município de Cachoeirinha, região físiográfica da Depressão Central do Estado do Rio Grande do Sul, situado a $29^{\circ} 55^{\prime} 30^{\prime \prime}$ de latitude Sul e a $50^{\circ} 58^{\prime} 21^{\prime \prime}$ de longitude Oeste e a $7 \mathrm{~m}$ de altitude. O solo da área experimental é classificado como Gleissolo Háplico Ta distrófico típico (Embrapa, 1999) e apresentou as seguintes características $(0-20 \mathrm{~cm}): 140 \mathrm{~g} / \mathrm{kg}$ de argila; $16 \mathrm{~g} / \mathrm{kg}$ de matéria orgânica; $9,8 \mathrm{mg} / \mathrm{L}$ de $\mathrm{P} ; 25 \mathrm{mg} / \mathrm{L}$ de K ; $1,2 \mathrm{cmol}_{\mathrm{c}} / \mathrm{L}$ de $\mathrm{Ca}$ e $0,4 \mathrm{cmol}_{\mathrm{C}} / \mathrm{L}$ de $\mathrm{Mg}$. O clima da região é do tipo subtropical úmido, conforme classificação de Köppen (Brasil, 1973), sendo considerado como de transição entre o $\mathrm{Cfa}_{1}$ (isoterma anual inferior a $18^{\circ} \mathrm{C}$ ) e $\mathrm{Cfa}_{2}$ (isoterma anual superior a $18^{\circ} \mathrm{C}$ ). As temperaturas médias do ar são de $14,3^{\circ} \mathrm{C}$ no mês mais frio (junho), e de $25,2^{\circ} \mathrm{C}$ no mês mais quente (janeiro), sendo a média anual de $19,6^{\circ} \mathrm{C}$. A precipitação pluvial média anual é de $1.398 \mathrm{~mm}$ (Ipagro, 1979).

Os tratamentos constaram de quatro genótipos de arroz irrigado e seis sistemas de cobertura de solo no inverno. Foram utilizados os genótipos BRS6, IRGA 416 e IRGA 417, de ciclo precoce (até 120 dias da emergência à maturação plena), e o genótipo BR-IRGA 409, de ciclo médio (121-135 dias), sendo todos caracterizados como do tipo moderno de plantas, de baixa estatura, com alto perfilhamento, com folhas curtas e eretas e grãos longofinos (Epagri, 1997).

Os genótipos de arroz foram implantados em semeadura direta em sucessão às gramíneas aveia-preta (Avena strigosa Scheib), aveia-branca (Avena sativa L.) e azevém (Lolium multiflorum Lam.), à leguminosa serradela nativa [Ornithopus micranthus (Benth.) Arechavaleta], à vegetação espontânea e ao sistema convencional (testemunha com solo desnudo), que caracterizaram os sistemas de cobertura de solo no inverno. O delineamento experimental utilizado foi o de blocos ao acaso, dispostos em parcelas subdivididas, com quatro repetições. Nas parcelas principais foram locados os sistemas de cobertura de solo no inverno e nas subparcelas, os genótipos de arroz.

$\mathrm{O}$ arroz foi estabelecido diretamente sobre as coberturas dessecadas pela aplicação do herbicida glifosate (4 L/ha de i.a.), aos 15 dias antes da semeadura. As datas de semeadura foram 14 de novembro de 1996, 4 de dezembro de 1997 e 23 de novembro de 1998 . O N foi aplicado em cobertura na dose de $100 \mathrm{~kg} / \mathrm{ha}$ de N, sendo $50 \%$ no perfilhamento e $50 \%$ na diferenciação do primórdio da panícula, utilizando-se a uréia como fonte. Na adubação de base foram aplicados $90 \mathrm{~kg} / \mathrm{ha}$ de $\mathrm{K}_{2} \mathrm{O}$ (cloreto de potássio) e $60 \mathrm{~kg} /$ ha de $\mathrm{P}_{2} \mathrm{O}_{5}$ (superfosfato triplo).

O controle de plantas daninhas foi realizado em pósemergência com aplicação dos herbicidas quinclorac (600 g/ha de i.a.) e propanil (1 L/ha de i.a.). As demais 
práticas de manejo foram realizadas conforme as recomendações técnicas da pesquisa do arroz irrigado para o Sul do Brasil (Irga, 1996; Epagri, 1997). A cada ano, após a colheita do arroz, foram semeadas as espécies de coberturas de inverno sobre a resteva do arroz, mantendo-se os tratamentos nas mesmas unidades experimentais nas três estações de crescimento. No cultivo convencional, o preparo do solo foi realizado com rotativa acoplada ao trator

Para determinação do rendimento de massa seca das espécies de cobertura de solo no inverno, foram feitas quatro amostragens de $0,25 \mathrm{~m}^{2}$ por parcela; as amostras foram colocadas a secar em estufa, à temperatura de $65^{\circ} \mathrm{C}$, até atingirem peso constante, e os resultados expressos em $\mathrm{g} / 0,25 \mathrm{~m}^{2}$. A população inicial de plantas de arroz foi obtida pela contagem de plantas em quatro repetições de $0,2 \mathrm{~m}^{2}$ em cada subparcela, 10 dias após a emergência, e os resultados, expressos em plantas $/ \mathrm{m}^{2}$.

Foram coletadas 20 plantas de arroz (parte aérea) por unidade experimental para avaliação de produção de massa seca e teor e quantidade de $\mathrm{N}$ acumulado no tecido aos 19, 33 e 20 dias após a emergência, respectivamente, nas estações de crescimento de 1996/97, 1997/98 e 1998/99. $\mathrm{O}$ teor de $\mathrm{N}$ foi determinado conforme Tedesco et al. (1995), e os resultados, expressos em porcentagem. A produção de massa seca por planta de arroz foi obtida pela pesagem de amostras colocadas a secar em estufa à temperatura de $65^{\circ} \mathrm{C}$, até atingirem peso constante. Os resultados de produção de massa seca e quantidade de $\mathrm{N}$ acumulado no tecido foram expressos em $\mathrm{mg} /$ planta e a quantidade de $\mathrm{N}$, obtida pelo produto entre produção de massa seca e teor de nitrogênio.

Para determinação da estatura da planta, foram tomadas 10 plantas por unidade experimental, medindo-se o comprimento da base da planta ao ápice da panícula, sendo os resultados expressos em centímetros. A partir de amostras de 20 panículas por unidade experimental (estações de crescimento de 1996/97 e 1997/98) e de 0,5 m de linha (estação de crescimento de 1998/99), foram obtidos o número de grãos formados por panícula, porcentagem de espiguetas estéreis e peso de 1.000 grãos (expresso em gramas). Para estimativa do rendimento de grãos foram colhidas amostras de uma área de $8 \mathrm{~m}^{2}$ por unidade experimental, nas quais se determinou o peso e umidade dos grãos, sendo os resultados expressos em t/ha, a 13\% de umidade.

A análise de variância dos dados foi realizada pelo teste F. Quando houve homogeneidade das variâncias, pelo teste de Bartlett, os dados foram submetidos à análise de variância conjunta, combinando-se as três estações de crescimento. Quando as variâncias foram heterogêneas, o que impossibilitou a análise conjunta dos dados, foi realizada a análise de variância dentro de cada estação de crescimento. Para comparação entre médias, foi utilizado o teste de Duncan, a $5 \%$ de probabilidade. As análises foram realizadas mediante o software estatístico para microcomputadores Irristat, versão 92-1, do International Rice Research Institute (Gomez et al., 1992).

\section{Resultados e Discussão}

O rendimento de massa seca das espécies de cobertura de inverno variou muito, com a estação de crescimento (Tabela 1). De maneira geral, nas três estações de crescimento, as espécies que melhor se estabeleceram foram o azevém e a serradela nativa. Ao se comparar as espécies de cobertura dentro de cada estação de crescimento, em 1996, o azevém e a aveia-preta foram as espécies que produziram mais massa seca, enquanto que em 1997 a aveia-preta apresentou maior rendimento de massa seca em relação às demais espécies de cobertura. Já na última estação de crescimento, a serradela nativa produziu mais massa seca em relação às demais espécies, uma vez que a aveia-preta teve que ser ressemeada e, desta forma, apresentou rendimento de massa seca muito aquém daquele obtido nas duas primeiras estações de crescimento. Em 1998, as duas espécies de aveia tiveram de ser ressemeadas em duas oportunidades face as precipitações pluviais intensas ocorridas logo após a semeadura, e apresentaram amarelecimento

Tabela 1. Rendimento $\left(\mathrm{g} / 0,25 \mathrm{~m}^{2}\right)$ de massa seca da parte aérea de quatro espécies de cobertura de solo no inverno e de vegetação espontânea, em três estações de crescimento. EEA-Irga, Cachoeirinha, $\mathrm{RS}^{(1)}$.

\begin{tabular}{|c|c|c|c|}
\hline \multirow{2}{*}{$\begin{array}{l}\text { Cobertura de solo } \\
\text { no inverno }\end{array}$} & \multicolumn{3}{|c|}{ Rendimento de massa seca } \\
\hline & 1996 & 1997 & 1998 \\
\hline Aveia-preta & $251 \mathrm{Aa}$ & $250 \mathrm{Aa}$ & $45 \mathrm{Bc}^{(2)}$ \\
\hline Aveia-branca & $184 \mathrm{Ab}$ & $93 \mathrm{Bc}$ & $90 \mathrm{Bbc}^{(2)}$ \\
\hline Azevém & $275 \mathrm{Aa}$ & $125 \mathrm{Bbc}$ & 142Bab \\
\hline Serradela nativa & $130 \mathrm{Abc}$ & $-(3)$ & $160 \mathrm{Aa}$ \\
\hline Veg. espontânea & $85 \mathrm{Bc}$ & $178 \mathrm{Ab}$ & 118Bab \\
\hline \multicolumn{4}{|c|}{$\begin{array}{l}\text { (1) Médias seguidas por letras distintas, maiúsculas na linha e minúsculas na } \\
\text { coluna, diferem estatisticamente pelo teste de Duncan, a } 5 \% \text { de probabili- } \\
\text { dade; médias de quatro amostragens por parcela; o coeficiente de variação } \\
\text { foi } 26,9 \% \text {. }{ }^{(2)} \text { Ressemeadura tardia das espécies de aveia. }{ }^{(3)} \text { Falta de ma- } \\
\text { terial representativo para a coleta, devido ao ataque de uma espécie de inse- } \\
\text { to que destruiu quase toda parte aérea das plantas. }\end{array}$} \\
\hline
\end{tabular}


ou morte de plantas durante os períodos de maior estresse hídrico.

No parâmetro população inicial de plantas de arroz, a análise conjunta evidenciou interação significativa entre sistemas de cobertura de solo no inverno e estações de crescimento (Tabela 2). Não houve interação significativa entre genótipos de arroz e estações de crescimento. Comparando-se as médias dentro de cada estação de crescimento, no tratamento em que o solo permaneceu desnudo durante o crescimento das plantas de arroz (sistema convencional), a população inicial de plantas foi maior em relação aos demais sistemas de cobertura de solo nas estações de crescimento de 1996/97 e 1998/99. Em 1997/98, a maior população inicial de plantas de arroz foi obtida quando em sucessão à aveia-preta. Silva et al. (1995) também encontraram menor população inicial de plantas de arroz no sistema de semeadura direta em relação ao sistema convencional.

Quanto a esta característica, o sistema convencional de semeadura é o que, teoricamente, proporciona melhores condições para emergência de plântulas, pois deixa o solo melhor preparado para a semeadura. Por outro lado, apesar das diversas vantagens que o solo com cobertura vegetal apresenta em relação ao sem-cobertura, algumas espécies podem apresentar efeitos inibitórios sobre a emergência de plântulas de arroz cultivadas em sucessão

Tabela 2. População inicial de plantas (número de plantas $/ \mathrm{m}^{2}$ ) de arroz em sucessão a seis sistemas de cobertura de solo no inverno, em três estações de crescimento, na média de quatro genótipos. EEA-Irga, Cachoeirinha, $\mathrm{RS}^{(1)}$.

\begin{tabular}{llll}
\hline \multirow{2}{*}{$\begin{array}{l}\text { Cobertura de solo } \\
\text { no inverno }\end{array}$} & \multicolumn{3}{c}{ População inicial de arroz } \\
\cline { 2 - 4 } & $1996 / 97$ & $1997 / 98$ & $1998 / 99$ \\
\hline Aveia-preta & $221 \mathrm{Cbc}$ & $472 \mathrm{Aa}$ & $384 \mathrm{Bb}$ \\
Aveia-branca & $274 \mathrm{Bab}$ & $417 \mathrm{Aab}$ & $389 \mathrm{Ab}$ \\
Azevém & $202 \mathrm{Bc}$ & $385 \mathrm{Ab}$ & $259 \mathrm{Bc}$ \\
Serradela nativa & $272 \mathrm{Bab}$ & $367 \mathrm{Ab}$ & $305 \mathrm{ABc}$ \\
Veg. espontânea & $278 \mathrm{Bab}$ & $361 \mathrm{Ab}$ & $269 \mathrm{Bc}$ \\
Testemunha & $329 \mathrm{Ba}$ & $349 \mathrm{Bb}$ & $544 \mathrm{Aa}$ \\
\hline
\end{tabular}

(1)Avaliação realizada aos dez dias após a emergência; médias seguidas por letras distintas, maiúsculas na linha e minúsculas na coluna, diferem estatisticamente pelo teste de Duncan, a $5 \%$ de probabilidade; o coeficiente de variação foi $25,9 \%$.
(Almeida, 1988), tanto como efeito físico da palha ou através da alelopatia. De acordo com Soares (1991), o azevém é uma espécie que apresenta efeito alelopático sobre arroz-vermelho, o qual pertence à mesma espécie do arroz cultivado (Oryza sativa L.), e assim, também pode afetar o arroz cultivado. Neste caso, talvez deva-se alterar o manejo desta espécie, como, por exemplo, aumentar o intervalo entre sua dessecação e a semeadura do arroz.

Nas determinações produção de massa seca, teor e quantidade de $\mathrm{N}$ acumulado na parte aérea por planta, a estatura de planta, o número de grãos formados por panícula, esterilidade de espiguetas e peso de 1.000 grãos não houve homogeneidade de variâncias nas três estações de crescimento pelo teste de Bartlett, impossibilitando, desta forma, a análise conjunta dos dados. Assim, para esses parâmetros, foram feitas análises individuais em cada estação de crescimento.

Na primeira estação de crescimento, as plantas de arroz em sucessão à serradela nativa foram as que apresentaram maior produção de massa seca (Tabela 3), provavelmente devido a maior disponibilidade inicial de $\mathrm{N}$ no solo proporcionado por esta espécie de cobertura, devido à menor relação $\mathrm{C} / \mathrm{N}$ das leguminosas em relação às gramíneas (Argenta et al., 1999). Em 1997/98 e 1998/99, as plantas de arroz desenvolvidas no tratamento sem vegetação (testemunha) produziram mais massa seca que as em sucessão às espécies de cobertura de solo no inverno (Tabela 3). Oliveira et al. (1994) também obtiveram menos massa seca por planta de arroz no sistema de semeadura direta em relação ao convencional. A resposta observada, tanto na população inicial como na produção de massa seca por planta de arroz pode estar relacionada, basicamente, aos efeitos químicos (alelopatia), físicos (efeito de cobertura) ou biológicos (população microbiana do solo) decorrentes da presença de resíduos vegetais no solo (Neves et al., 1998).

O teor de $\mathrm{N}$ na planta de arroz não variou entre os tratamentos na estação de crescimento de 1996/97 (Tabela 3). Em 1997/98, o seu teor foi superior nas plantas de arroz em sucessão à aveia-branca, enquanto na última estação de crescimento, o arroz cultivado em sucessão à serradela nativa apresentou maior teor de $\mathrm{N}$ em relação às plantas dos demais sistemas de cobertura de solo. 
Tabela 3. Produção de massa seca (MS) e teor de nitrogênio (N) da parte aérea por planta de arroz em sucessão a seis sistemas de cobertura de solo no inverno, em três estações de crescimento, na média de quatro genótipos. EEA-Irga, Cachoeirinha, $\mathrm{RS}^{(1)}$.

\begin{tabular}{|c|c|c|c|c|c|c|}
\hline \multirow{2}{*}{$\begin{array}{l}\text { Cobertura de solo } \\
\text { no inverno }\end{array}$} & \multicolumn{2}{|c|}{$1996 / 97$} & \multicolumn{2}{|c|}{$1997 / 98$} & \multicolumn{2}{|c|}{$1998 / 99$} \\
\hline & MS (mg/planta) & $\mathrm{N}(\%)$ & MS (mg/planta) & $\mathrm{N}(\%)$ & MS (mg/planta) & $\mathrm{N}(\%)$ \\
\hline Aveia-preta & $43,0 \mathrm{~cd}$ & $2,47 \mathrm{a}$ & $380,0 \mathrm{~b}$ & $2,31 \mathrm{ab}$ & $74,0 \mathrm{abc}$ & $2,82 b$ \\
\hline Aveia-branca & $54,0 \mathrm{~b}$ & $2,64 \mathrm{a}$ & $455,0 \mathrm{ab}$ & $2,43 a$ & $62,0 \mathrm{c}$ & $2,64 b$ \\
\hline Azevém & $37,5 d$ & $2,29 \mathrm{a}$ & $415,0 \mathrm{~b}$ & $2,27 \mathrm{ab}$ & $66,0 \mathrm{bc}$ & $2,90 \mathrm{~b}$ \\
\hline Serradela nativa & $82,0 \mathrm{a}$ & $2,81 \mathrm{a}$ & $465,0 \mathrm{ab}$ & $2,22 \mathrm{ab}$ & $84,0 \mathrm{ab}$ & $3,94 \mathrm{a}$ \\
\hline Vegetação espontânea & $51,5 \mathrm{~d}$ & $2,73 a$ & $400,0 \mathrm{~b}$ & $2,28 \mathrm{ab}$ & $66,0 \mathrm{bc}$ & $2,76 \mathrm{~b}$ \\
\hline Testemunha & $41,5 \mathrm{~d}$ & $2,99 \mathrm{a}$ & $550,0 \mathrm{a}$ & $2,12 \mathrm{~b}$ & $90,5 \mathrm{a}$ & $2,51 \mathrm{~b}$ \\
\hline $\mathrm{CV}(\%)$ & 19,2 & 31,9 & 37,1 & 13,5 & 17,4 & 21,8 \\
\hline
\end{tabular}

(1)Médias seguidas por letras distintas na coluna diferem estatisticamente pelo teste de Duncan, a $5 \%$ de probabilidade; avaliado em plantas coletadas aos 19 dias (1996/97), aos 33 dias (1997/98) e aos 20 dias (1998/99) após a emergência.

A quantidade de $\mathrm{N}$ acumulado por planta de arroz nas estações de crescimento de 1996/97 e 1998/99 variou somente em função de sistemas de cobertura de solo no inverno (Tabela 4). Nestes anos, a quantidade de $\mathrm{N}$ acumulado foi maior no arroz cultivado em sucessão à serradela nativa em relação aos demais sistemas de cobertura de solo no inverno, evidenciando a contribuição desta leguminosa através da fixação simbiótica do $\mathrm{N}$ atmosférico. Plantas da família das leguminosas do gênero Ornithopus, no qual está incluída a serradela nativa, são preferidas por bactérias simbiontes da espécie Rhizobium lupini (Bray, 1983). Estes resultados estão de acordo com os obtidos por Argenta et al. (1999), que encontraram maior quantidade de $\mathrm{N}$ acumulado em grãos de milho cultivado em semeadura direta em sucessão à ervilhaca comum do que em sucessão à aveia-preta, tanto a 1 dia, como aos 20 dias após a dessecação das coberturas. Em 1997/98 não houve variação entre os tratamentos para este parâmetro, devido à coleta tardia do material a campo, uma vez que já havia sido feita a primeira aplicação de $\mathrm{N}$, que nivelou sua quantidade acumulada nas plantas entre os sistemas de cobertura do solo.

Quanto às variáveis estatura de planta, número de grãos formados por panícula, esterilidade de espiguetas e peso de 1.000 grãos, foram significativos apenas os efeitos simples de genótipos nas três estações de crescimento (Tabela 5). Os resultados foram de acordo com as características genéticas de
Tabela 4. Quantidade de nitrogênio (N) acumulado (mg/planta) na parte aérea por planta de arroz em sucessão a seis sistemas de cobertura de solo no inverno, em três estações de crescimento, na média de quatro genótipos. EEA-Irga, Cachoeirinha, $\mathrm{RS}^{(1)}$.

\begin{tabular}{lcrc}
\hline \multirow{2}{*}{$\begin{array}{l}\text { Cobertura de solo } \\
\text { no inverno }\end{array}$} & \multicolumn{3}{c}{$\mathrm{N}$ acumulado pelo arroz } \\
\cline { 2 - 4 } & $1996 / 97$ & $1997 / 98$ & $1998 / 99$ \\
\hline Aveia-preta & $1,08 \mathrm{bc}$ & $8,80 \mathrm{a}$ & $2,12 \mathrm{~b}$ \\
Aveia-branca & $1,42 \mathrm{~b}$ & $11,05 \mathrm{a}$ & $1,67 \mathrm{~b}$ \\
Azevém & $0,88 \mathrm{c}$ & $9,45 \mathrm{a}$ & $2,02 \mathrm{~b}$ \\
Serradela nativa & $2,33 \mathrm{a}$ & $10,50 \mathrm{a}$ & $3,48 \mathrm{a}$ \\
Veg. espontânea & $1,39 \mathrm{bc}$ & $9,15 \mathrm{a}$ & $1,79 \mathrm{~b}$ \\
Testemunha & $1,24 \mathrm{bc}$ & $11,80 \mathrm{a}$ & $2,26 \mathrm{~b}$ \\
\hline CV $(\%)$ & 45,1 & 38,0 & 27,1 \\
\hline
\end{tabular}

(1)Avaliado em plantas coletadas aos 19 dias (1996/97), aos 33 dias (1997/98) e aos 20 dias (1998/99) após a emergência; médias seguidas por letras distintas na coluna diferem estatisticamente pelo teste de Duncan, a $5 \%$ de probabilidade.

cada genótipo, uma vez que não houve interação significativa entre genótipos de arroz e sistemas de cobertura de solo no inverno. Silva et al. (1995) também não encontraram interação entre genótipos e sistemas de semeadura, ao compararem os sistemas de semeadura direta com cultivo mínimo e convencional.

A análise conjunta dos dados indicou que para rendimento de grãos somente houve interação entre sistemas de coberturas de solo no inverno e estações de crescimento (Tabela 6). Nas três estações de crescimento, não houve interação entre genótipos e sis- 


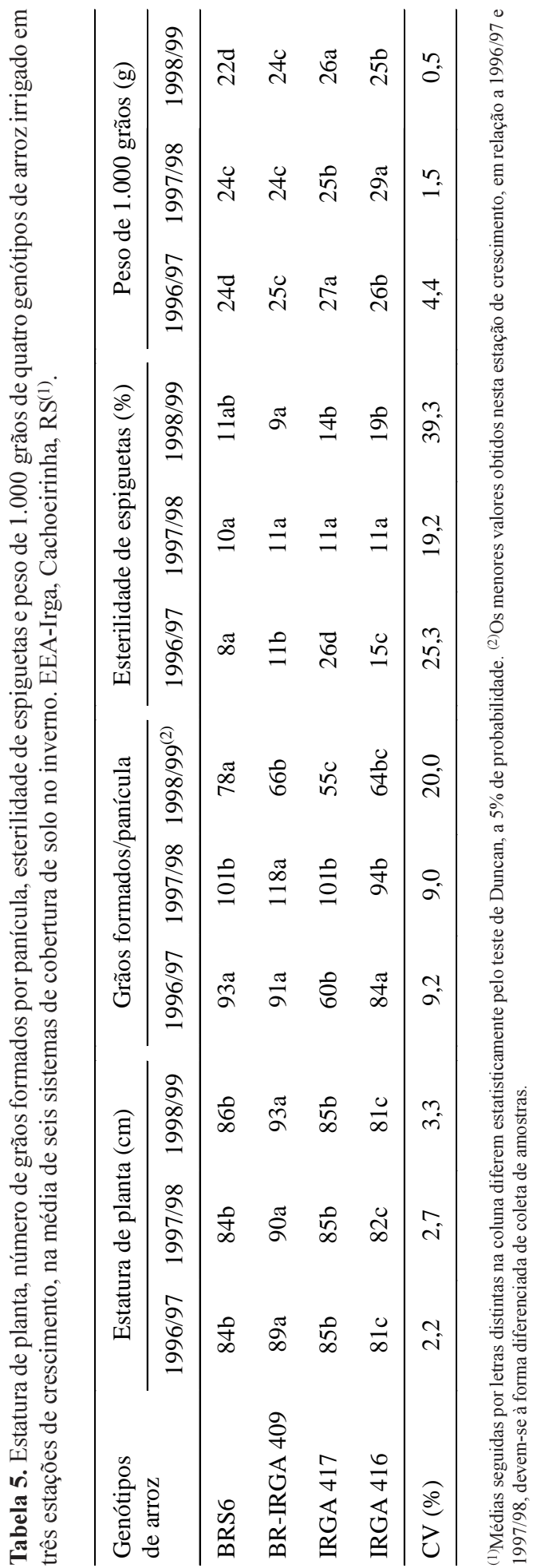

Tabela 6. Rendimento (t/ha) de grãos de arroz irrigado em sucessão a seis sistemas de cobertura de solo no inverno, em três estações de crescimento, na média de quatro genótipos. EEA-Irga, Cachoeirinha, $\mathrm{RS}^{(1)}$.

\begin{tabular}{lccl}
\hline \multirow{2}{*}{$\begin{array}{l}\text { Cobertura de solo } \\
\text { no inverno }\end{array}$} & \multicolumn{3}{c}{ Rendimento de grãos de arroz } \\
\cline { 2 - 4 } & $1996 / 97$ & $1997 / 98$ & $1998 / 99$ \\
\hline Aveia-preta & $6,2 \mathrm{Bab}$ & $6,9 \mathrm{Ad}$ & $6,8 \mathrm{Aa}$ \\
Aveia-branca & $6,3 \mathrm{Ba}$ & $7,6 \mathrm{Abc}$ & $6,8 \mathrm{Ba}$ \\
Azevém & $5,8 \mathrm{Bb}$ & $7,2 \mathrm{Abcd}$ & $6,2 \mathrm{Bb}$ \\
Serradela nativa & $6,5 \mathrm{Ba}$ & $7,7 \mathrm{Aab}$ & $6,4 \mathrm{Bab}$ \\
Veg. espontânea & $6,4 \mathrm{Ba}$ & $7,1 \mathrm{Acd}$ & $6,8 \mathrm{Ba}$ \\
Testemunha & $6,4 \mathrm{Ba}$ & $8,1 \mathrm{Aa}$ & $6,7 \mathrm{Bab}$ \\
\hline
\end{tabular}

${ }^{(1)}$ Médias seguidas por letras distintas, maiúsculas na linha e minúsculas na coluna, diferem estatisticamente pelo teste de Duncan, a 5\% de probabilidade; o coeficiente de variação foi $10,2 \%$.

temas de cobertura do solo no inverno. Somente o arroz cultivado em sucessão à serradela nativa apresentou rendimento de grãos similar ao obtido no sistema de cultivo convencional nas três estações de crescimento.

Quando o azevém foi utilizado como cobertura de solo, o rendimento de grãos de arroz foi inferior ao do arroz cultivado no sistema convencional, nas três estações de crescimento. Nas estações de crescimento de 1996/97 e 1998/99, o arroz em sucessão às duas espécies de aveia apresentou rendimento de grãos similar ao da testemunha com solo desnudo, e apenas em 1997/98, especialmente em relação ao arroz em sucessão à aveia-preta, o rendimento de grãos foi inferior ao da testemunha.

A maior quantidade de $\mathrm{N}$ acumulado na planta de arroz cultivado em sucessão à serradela nativa (Tabela 4) foi compensada pela aplicação de adubação nitrogenada no arroz, uma vez que todos os tratamentos receberam $\mathrm{N}$ em cobertura, e desta forma, nenhum tratamento apresentou rendimento de grãos superior ao da testemunha, nas três estações de crescimento.

\section{Conclusões}

1. O rendimento de grãos de arroz em sucessão à serradela nativa é similar ao obtido no sistema convencional. 
2. O arroz cultivado em sucessão ao azevém apresenta rendimento de grãos inferior ao obtido no sistema convencional.

\section{Referências}

ALMEIDA, F. S. de. A alelopatia e as plantas. Londrina: Iapar, 1988. $60 \mathrm{p}$.

ARGENTA, G.; SILVA, P. R. F. da; RIZZARDI, M. A.; BARUFFI, M. J.; LOPES, M. C. B. Manejo do nitrogênio no milho em semeadura direta em sucessão a espécies de cobertura de solo no inverno e em dois locais: II. Efeito sobre o rendimento de grãos. Ciência Rural, Santa Maria, v. 29, n. 4, p. 587-593, 1999.

BALOTA, E. L.; ANDRADE, D. S.; COLOZZI FILHO, A. Avaliações microbiológicas em sistemas de preparo do solo e sucessão de culturas. Plantio Direto, Passo Fundo, n. 35, p. 21-22, set./out.1996.

BRASIL. Ministério da Agricultura. Levantamento de reconhecimento de solos do Estado do Rio Grande do Sul. Recife, 1973. 431 p. (Boletim Técnico, 30).

BRAY, C. M. Nitrogen metabolism in plants. New York: Longman, 1983. cap. 1.

DA ROS, A. O.; AITA, C. Efeito de espécies de inverno na cobertura do solo e fornecimento de nitrogênio ao milho em plantio direto. Revista Brasileira de Ciência do Solo, Campinas, v. 20, n. 1, p. 135-140, 1996.

DIAS, A. D.; GOMES, A. da S.; PEÑA, Y. A.; SOUZA, R. O. Desempenho do arroz irrigado em plantio direto sob diferentes coberturas vegetais. In: REUNIÃO DA CULTURA DO ARROZ IRRIGADO, 21., 1995, Porto Alegre. Anais... Porto Alegre: Irga, 1995. p. 146-149.

EMBRAPA. Centro Nacional de Pesquisa de Solos (Rio de Janeiro, RJ). Sistema brasileiro de classificação de solos. Brasília: Embrapa-SPI, 1999. 412 p.

EPAGRI. Estação Experimental de Itajaí. Arroz irrigado: recomendações técnicas da pesquisa para o Sul do Brasil. 4. ed. Itajaí, 1997. 80 p.

FAY, P. K.; DUKE, W. B. An assessment of allelopathic potential in Avena germplasm. Weed Science, Champaign, v. 25 , n. 3 , p. $224-228,1977$.

GOMEZ, K. A.; BARTOLOME, V. I.; ULPINDO, E. C.; CALINGA, R. T. IRRISTAT user's manual: version 92-1: biometrics unit. Manila: International Rice Research Institute, 1992. $121 \mathrm{p}$
IPAGRO (Porto Alegre, RS). Guaíba. In: . Observações meteorológicas no Estado do Rio Grande do Sul Porto Alegre, 1979. p. 55-66. (Boletim Técnico, 3).

IRGA. Estação Experimental do Arroz (Cachoeirinha, RS). Arroz irrigado: recomendações técnicas da pesquisa para o Sul do Brasil. 3. ed. Cachoeirinha, 1996. 88 p.

MENEZES, V. G.; ANDRES, A.; SOUZA, P. R. de; CARRÃO, V. H. Serradela nativa: uma alternativa de inverno para as várzeas do sul do Brasil. Lavoura Arrozeira, Porto Alegre, v. 47, n. 415, p. 19-22, 1994.

NEVES, R.; FLECK, N. G.; MENEZES, V. G.; VIDAL, R. A. Interferência do arroz vermelho, dessecado por herbicidas não seletivos, no arroz irrigado: I. Estabelecimento e desenvolvimento das plantas. Pesquisa Agropecuária Gaúcha, Porto Alegre, v. 4, n. 2, p. 173 $181,1998$.

NEVES, R.; FLECK, N. G.; VIDAL, R. A. Intervalo de tempo para semeadura de milho pós-dessecação da cobertura de aveia-preta com herbicidas. Ciência Rural, Santa Maria, v. 29, n. 4, p. 603-608, 1999.

OLIVEIRA, J. C. S. de; MARCHEZAN, E.; STORK, L.; MACHADO, S. L. de O. Sistemas de preparo do solo para o arroz irrigado (Oryza sativa L.). Ciência Rural, Santa Maria, v. 24, n. 3, p. 489-493, 1994.

PAULETTO, E. A.; GOMES, A. da S.; SOUZA, R. O.; VAHL, L. C.; SILVA, J. B. da. Produtividade do arroz irrigado cultivado sob diferentes sistemas de preparo do solo e de rotação e sucessão de culturas. In: CONGRESSO BRASILEIRO DE ARROZ IRRIGADO, 1.; REUNIÃO DA CULTURA DO ARROZ IRRIGADO, 23., 1999, Pelotas. Anais... Pelotas: Embrapa-CPACT, 1999. p. 246249.

PAVINATO, A.; AITA, C.; CERETTA, C. A.; BEVILÁQUA, G. P. Resíduos culturais de espécies de inverno e o rendimento de grãos de milho no sistema de cultivo mínimo. Pesquisa Agropecuária Brasileira, Brasília, v. 29, n. 9, p. 1427-1432, set. 1994.

RUEDELL, J. Plantio direto na região de Cruz Alta. Cruz Alta: Fundacep/Basf/Fecotrigo, 1995. 134 p.

SILVA, P. R. F. da; MENEZES, V. G.; MARIOT, C. H. P.; CARMONA, R. de C.; REZERA, F. Comparação de cultivares de arroz irrigado nos sistemas de semeadura convencional e em cultivo mínimo. In: REUNIÃO DA CULTURADO ARROZ IRRIGADO, 21., 1995, Porto Alegre. Anais... Porto Alegre: Irga, 1995. p. 155-156. 
SILVEIRA, P. M. da; ZIMMERMANN, F. J. P.; AMARAL, A. M. do. Efeito da sucessão de cultura e do preparo do solo sobre o rendimento do arroz de sequeiro. Pesquisa Agropecuária Brasileira, Brasília, v. 33, n. 6 , p. 885-890, jun. 1998.

SOARES, A. L. A. Plantio direto de arroz irrigado: considerações sobre o ciclo completo. Plantio direto de arroz irrigado. [S.1.]: Monsanto do Brasil, 1991. p. 4-15.
TEDESCO, M. J.; GIANELLO, C.; BISSANI, C. A.; BOHNEN, H.; WOLKWEISS, S. J. Análise de solo, plantas e outros materiais. 2. ed. Porto Alegre: UFRGS, 1995. $174 \mathrm{p}$.

VICTORIA, R. L.; PICCOLO, M. C.; VARGAS, A. A. T. O ciclo do nitrogênio. In: CARDOSO, E. J. B. N.; TSAI, S. M.; NEVES, M. C. P. (Coord.). Microbiologia do solo. Campinas: Sociedade Brasileira de Ciência do Solo, 1992. p. $105-119$. 